\title{
EFEITOS DA ADMINISTRAÇÃO PÓS NATAL DE LIPOPOLISSACARIDEO NO DIMORFISMO SEXUAL DA PROLE DE RATOS
}

\author{
Amanda Florentina do NASCIMENTO ${ }^{1 *}$, Maria Martha BERNARDI ${ }^{2}$, Sheila Silva RODRIGUES ${ }^{1}$ \& Luciano \\ Freitas FELÍ́CIO ${ }^{1}$ \\ ${ }^{1}$ Faculdade de Medicina Veterinária e Zootecnia da Universidade de São Paulo, Departamento de Patologia. São Paulo, \\ Brasil. \\ ${ }^{2}$ Universidade Paulista, Instituto de Ciências da Saúde. São Paulo, Brasil. \\ *Autor para correspondência: amandafdonascimento@gmail.com \\ http://dx.doi.org/10.18571/acbm.082
}

\section{RESUMO}

Processos inflamatórios no período pré e pós-natal estariam envolvidos com expressões de comportamentos em animais de laboratório e, em humanos, com doenças psiquiátricas. Neste sentido, já se mostrou também que doenças psiquiátricas são dependentes do gênero. $\mathrm{O}$ lipopolissacarídeo (LPS) é uma endotoxina bacteriana empregada como ativador do sistema imune. A administração em período precoce da vida de ratos promove alterações quando desafiados na idade adulta com a mesma endotoxina. No sentido de investigar estas diferenças, este trabalho examinou diferenças sexuais em ratos cujo sistema imune foi ativado no quinto dia pós-natal (PND5) por LPS. Assim, ratos machos e fêmeas receberam no PND5 $50 \mu \mathrm{g} / \mathrm{kg}$ de LPS i.p. ou o seu veículo e na idade adulta, fêmeas e machos tratados ou não pós-natalmente com LPS, receberam 100 $\mu \mathrm{g} / \mathrm{kg}$ de LPS i.p e foram observados o peso e a atividade geral em campo aberto. Os resultados mostraram que: 1) Na infância o tratamento com LPS não modificou o peso corporal e a atividade geral dos animais; 2) Na idade adulta observou-se aumento da frequência de locomoção e levantar nas ratas tratadas pós-natalmente com LPS em relação aos animais machos do mesmo grupo. Conclui-se, portanto que fêmeas expostas pós-natalmente com LPS apresentam maior tolerância a uma segunda dose de LPS na idade adulta com relação aos animais machos que receberam o mesmo tratamento.

Palavras chave: LPS, Inflamação, Comportamento, Dimorfismo sexual.

\begin{abstract}
As evidenced in several instances, inflammatory process within the pre- and postnatal period may cause the expression of psychiatric disease behaviour. Lipopolysaccharide (LPS) is a bacterian endotoxin, frequently used in biomedical experiments, is an activator of the immunological system. Administration of this endotoxin in an early life stage in rats can provoke alteration in the exploratory behavior when challenged with the same endotoxin later in life. The main objective of this study was to analyze sexual differences in rats, whose immune system was activated by LPS in the fifth postnatal day (PND5), and the consequences of this treatment for explorative behaviour in adulthood. To achieve these goals, male and female rats received $50 \mu \mathrm{g} / \mathrm{kg}$ of LPS on PND5. The rats were observed until the day 21. On PND21 the general activity of treated rats was assessed and compared with the control group of animals. In adult age, a challenge dose of LPS $(100 \mu \mathrm{g} / \mathrm{Kg})$ was administered to all groups. The behaviour was analyzed two hours post treatment in the open field. The LPS treatment on PND5 was unable to alter the body weight
\end{abstract}


and general activity. The LPS challenge increased locomotion and rearing frequencies only in female rats postnatally exposed to the endotoxin. Thus, it was suggested that postnatal LPS exposure produces tolerance to a challenge dose in adult age in female rats as opposed to similarly-treated male rats.

Keywords: LPS, Inflammation, Behavior, Sexual Dimorphism.

\section{Introdução}

É fato conhecido à existência de dimorfismo sexual em vários aspectos da biologia dos animais e do homem. Neste sentido, não só o aspecto físico, o comportamento e a fisiologia fazem parte deste fenômeno. A literatura aponta também que a susceptibilidade à doença está relacionada ao gênero (AFIFI, 2007). A ansiedade ocorre com mais frequência em mulheres que em homens, provavelmente decorrente da ação de hormônios reprodutivos e o ciclo hormonal (PIGOTT, 2003). Ainda, embora controverso, existem dados na literatura de que a esquizofrenia ocorre mais tardiamente em mulheres que em homens (RIECHER-RÃSSLER \& HÃFNER, 2000). Estes dados são indicativos de que a manifestação de doenças parece ser sexualmente dimórfica. Segundo Alves \& Palermo Neto (2007) o estudo das interações entre os sistemas imune (SI) e nervoso central (SNC) acabou por resultar na concepção de uma grande área de pesquisa conhecida como Neuroimunomodulação, que estuda como esses sistemas influenciam-se mutuamente, com evidentes implicações fisiológicas e patológicas. O lipopolissacárideo (LPS) é um constituinte pertence às paredes celulares de bactérias gram-negativas, quando o LPS entra em contato com o organismo, inicia-se uma série de respostas no organismo infectado, podendo atuar em células como os monócitos, neutrófilos, plaquetas sanguíneas e células endoteliais, mas, sem dúvidas, os macrófagos são as principais estruturas onde o mecanismo de ação do LPS é deflagrado. Pelo fato de liberar citocinas, o LPS é usado já há muitos anos como ativador de resposta imune, principalmente na resposta imune inata (inespecífica) com os macrófagos. Gayle et al (2003) sugeriram que as citocinas liberadas pela resposta inflamatória ao LPS seriam responsáveis pela ativação do eixo hipotálamo-hipófise-adrenal estando, pelo menos parcialmente envolvidas nas lesões promovidas pela inflamação no cérebro de ratos. Tenk et al (2008) demonstraram que a ativação imune com LPS durante o período precoce pós-natal altera o dimorfismo sexual no comportamento exploratório na idade adulta, quando as proles femininas e masculinas são desafiadas com a mesma endotoxina, sendo um indício importante de diferenças na susceptibilidade a infecções dependentes do sexo. Portanto o objetivo deste trabalho foi investigar os efeitos da ativação do sistema imune em períodos precoces da vida da prole feminina e masculina de ratas em modelos comportamentais sexualmente dimórficos. Investigou-se também, estas respostas comportamentais frente a um novo desafio imune para melhor caracterizar possíveis diferenças na sensibilidade ao LPS no dimorfismo sexual. O período de tratamento (PND5) foi escolhido por corresponder ao primeiro ano de vida de um bebê humano (BERNARDI, 2006). A dose pós-natal $(50 \mu \mathrm{g} / \mathrm{kg})$ foi selecionada a partir de estudo prévio mostrando interferências no dimorfismo sexual da prole de ratos; a dose de $100 \mu \mathrm{g} / \mathrm{kg}$ administrada na idade adulta, foi utilizada baseada no trabalho de Nascimento et al (2013), que mostrou ser essa dose capaz de produzir comportamento doentio em ratas lactantes. Estes fatos podem ter um significado clínico, pois fêmeas e machos expostos a infecções no período pós-natal podem apresentar também diferentes susceptibilidade a patógenos na idade adulta. 


\section{Biomédica Brasiliensia}

ISSN: 2236-0867

\section{Materiais e Métodos}

\subsection{Animais}

Foram utilizados ratas Wistar prenhes provenientes do biotério da Faculdade de Medicina Veterinária e Zootecnia da Universidade de São Paulo - FMVZ - USP. Todos os procedimentos foram submetidos à Comissão de Bioética da FMVZ com protocolo n. ${ }^{\circ}$ 1881/2010. As fêmeas foram mantidas isoladas em gaiolas de polipropileno medindo $17 \times 27 \times 14 \mathrm{~cm}$. Estas foram colocadas em biotério, luz controlada com ciclo claro/escuro de 12 horas, temperatura constante. Água e comida foram fornecidas aos animais ad libitum. Ao nascimento da prole foi feita a padronização das ninhadas em 8 filhotes por fêmea, sendo, quando possível, 4 fêmeas e 4 machos. O período de amamentação foi de 21 dias. Após o desmame, os filhotes foram separados por sexo e tratamento, e alojados em gaiolas de polipropileno, sendo mantidos nas mesmas condições laboratoriais de suas mães.

\subsection{Drogas e soluções}

LPS: lipopolissacarídeo obtido por extração fenólica a partir da Escherichia coli, sorotipo 0127:B8 (Sigma). Solução Salina: solução estéril de cloreto de sódio a 0,9\%

\subsection{Procedimentos pós-natal}

As proles masculina e feminina de ratas foram divididas em dois grupos: um controle e outro experimental com 7 animais cada. Os animais do grupo experimental receberam no PND5 $50 \mu \mathrm{g} / \mathrm{kg}$ de LPS por via i.p. e aqueles do grupo controle, o veículo do LPS pela mesma via. Durante a lactação os filhotes foram pesados e ao desmame (21 dias) sua atividade geral observada em campo aberto. No PND75, das proles de animais tratados ou não no PND5 com LPS (50 $\mu \mathrm{g} / \mathrm{Kg}$ ) foram selecionados 7 animais de cada grupo experimental e controle, machos e fêmeas, os quais receberam por via i.p. $100 \mu \mathrm{g} / \mathrm{Kg}$ de LPS. Duas horas após a administração desta endotoxina, estes ratos e ratas foram observados no campo aberto para a medida de sua atividade geral.

\subsection{Atividade geral em campo aberto}

Neste teste os animais foram colocados em um campo aberto sempre durante um mesmo período do dia. Cada animal escolhido (1 fêmea e 1 macho/ ninhada), foi colocado individualmente no centro do aparelho de campo aberto, sendo observado por 3 minutos. O campo aberto para filhotes de ratos foi construído segundo o modelo descrito por Broadhurst (1960), e adaptado para filhotes de ratos e para camundongos, e consiste de uma arena de madeira, medindo $40 \mathrm{~cm}$ de diâmetro x $40 \mathrm{~cm}$ de altura, pintada de branco. O fundo deste aparelho é dividido em vinte e cinco partes aproximadamente iguais. Já o campo aberto para ratos adultos, consiste em uma arena de madeira, medindo $97 \mathrm{~cm}$ de diâmetro por $30 \mathrm{~cm}$ de altura, pintada de branco, dividida em 19 partes. Entre um animal e outro, o aparelho é limpo com solução de álcool a 5\% para evitar-se a interferência do odor do animal anterior. Observou-se a frequência de locomoção, de levantar, e o número de bolos fecais (defecação). Definiu-se unidade de locomoção o ato de o animal penetrar com as quatro patas em uma das divisões do chão da arena; unidade de levantar corresponde à postura de o animal permanecer apoiado nas patas posteriores, com o tronco perpendicular ao chão, 
tendo a cabeça dirigida para cima, podendo ou não ter tocar com as patas dianteiras as paredes do campo aberto; cada bolo de fezes produzido pelo animal durante o período de teste foi registrado como unidade de defecação. $\mathrm{O}$ registro da frequência dos parâmetros foi feito por intermédio de um contador manual. O tempo de imobilidade (freezing) também foi medido sendo que a imobilidade é definida quando o animal não apresenta locomoção e sem movimentos de farejar. Este parâmetro foi medido com o auxílio de um cronômetro.

\subsection{Análise Estatística}

Antes de qualquer procedimento experimental foi aplicado o teste de Bartlet para verificar a homocedasticidade dos dados. A partir deste dado, foram utilizados testes de comparação de médias, a ANOVA de uma via ou de duas vias quando se aplicarem. A probabilidade de $\mathrm{p}<0,05$ foi considerada capaz de revelar diferenças significantes

\section{Resultados}

\subsection{Peso Corporal}

A figura 1 ilustra os efeitos da administração pós-natal de LPS $(50 \mu \mathrm{g} / \mathrm{Kg})$ no PND5 no peso corporal de ratos avaliado do PND5 ao PND21. A ANOVA de duas vias aplicada ao peso dos animais indicou que os dias alteraram o resultado $\mathrm{F}(2 / 72)=321,09, \mathrm{P}<0.0001$, não houve alteração entre os grupos $\mathrm{F}(3 / 72)=0.51, \mathrm{P}=0.67$, não havendo interação $\mathrm{F}(6 / 72)=0.49, \mathrm{P}=0.81$.

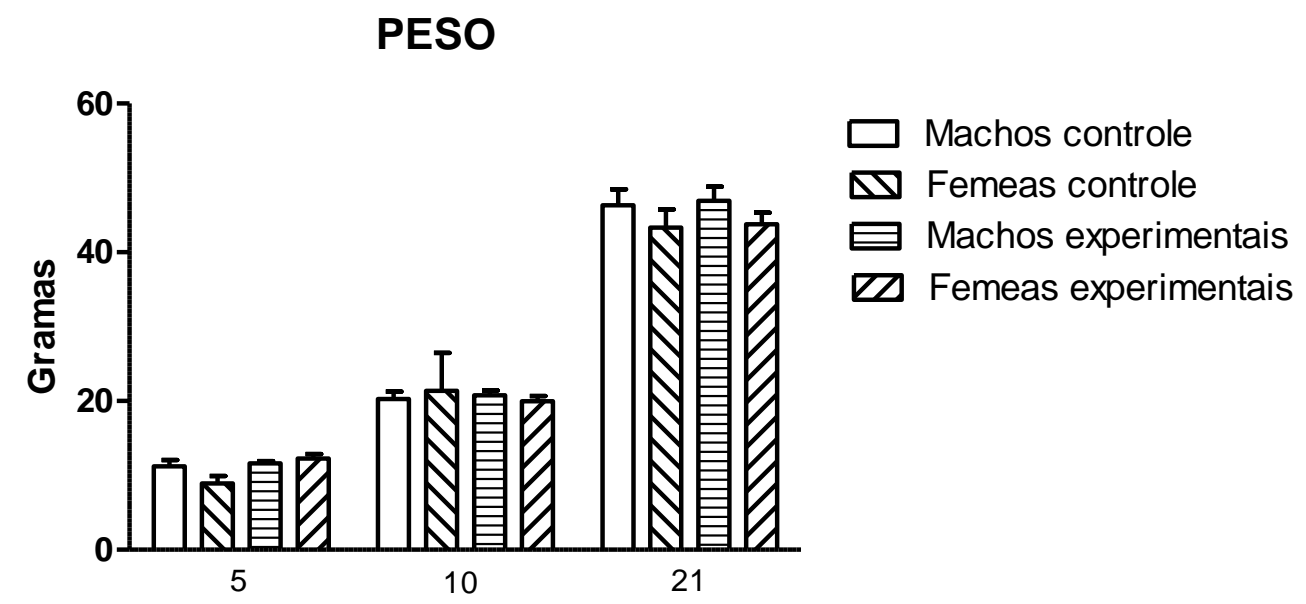

Dias de observação

Figura 1: Efeitos da administração pós-natal de lipopolissacárideo (LPS-50) no quinto dia da lactação no peso corporal de ratos machos no $5^{\circ}, 10 .^{\circ}$ e $21^{0}$ dias de vida. São apresentadas as médias e respectivos erros-padrão. $\mathrm{N}=7 /$ grupo.

ANOVA de duas vias. 


\subsection{Atividade Geral em Campo aberto no PND21}

As figuras - (2-5) ilustram os efeitos da administração pós-natal de lipopolissacarídeo (LPS) no PND5 na atividade geral de ratos machos e fêmeas observados em campo aberto no PND21.

A ANOVA de duas vias aplicada à frequência de locomoção indicou que o tratamento e o sexo não alteraram o resultado $(\mathrm{F}(1 / 24)=0.17, \mathrm{P}=0.68),(\mathrm{F}(1 / 24)=0.17, \mathrm{P}=0.68)$ não havendo interação entre os fatores $(\mathrm{F}(1 / 24)=0.54, \mathrm{P}=0.46)$. Mesmos resultados foram obtidos para as frequências de levantar [tratamento e o sexo não alteraram o resultado $(\mathrm{F}(1 / 24)=0.01, \mathrm{P}=0.90)$, $(\mathrm{F}(1 / 24)=0.01, \mathrm{P}=0.90)$ não havendo interação entre os fatores $(\mathrm{F}(1 / 24)=0.10, \mathrm{P}=0.75)]$, duração de imobilidade [tratamento e o sexo não alteraram o resultado $(\mathrm{F}(1 / 24)=0.02, \mathrm{P}=0.88)$, $(\mathrm{F}(1 / 24)=0.05, \mathrm{P}=0.82)$ não havendo interação entre os fatores $(\mathrm{F}(1 / 24)=0.02, \mathrm{P}=0.89] \mathrm{e}$ frequência de defecação [ tratamento e o sexo não alteraram o resultado $(\mathrm{F}(1 / 24)=0.55, \mathrm{P}=0.46)$, $(\mathrm{F}(1 / 24)=0.55, \mathrm{P}=0.46)$ havendo interação entre os fatores $(\mathrm{F}(1 / 24)=4.83, \mathrm{P}=0.03)]$.

\section{Locom oção}

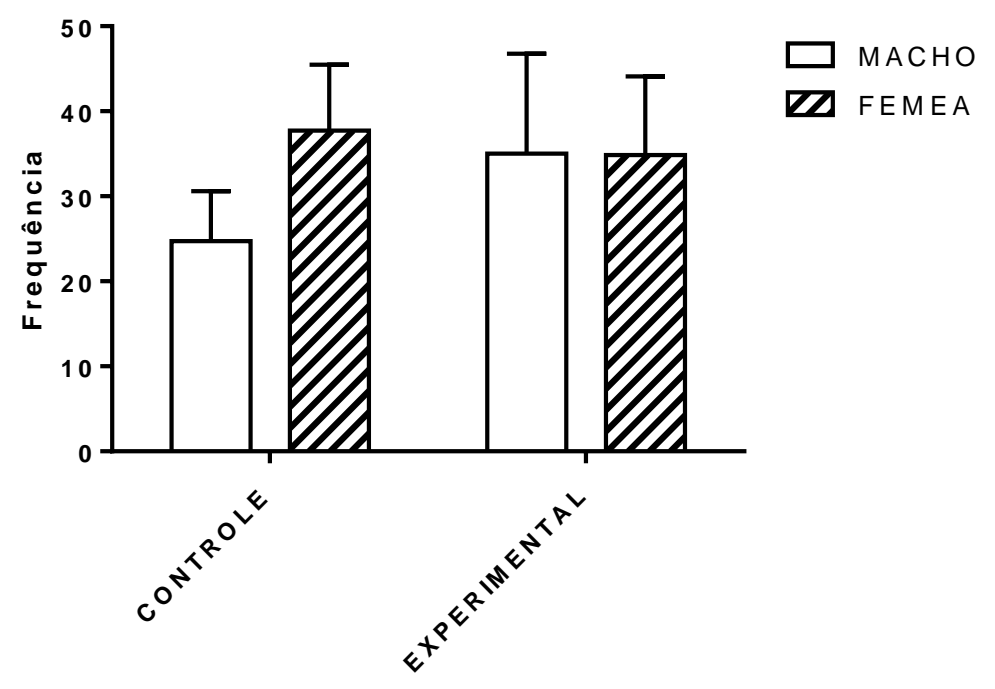

Figura 2: Efeitos da administração pós-natal de lipopolissacarídeo (LPS-50 $\mu \mathrm{g} / \mathrm{Kg}$ ) no quinto dia da lactação na frequência de locomoção de ratos machos e fêmeas observados em campo aberto no PND21. São apresentadas as médias e respectivos erros-padrão. $\mathrm{N}=7$ /grupo. ANOVA de duas vias. 


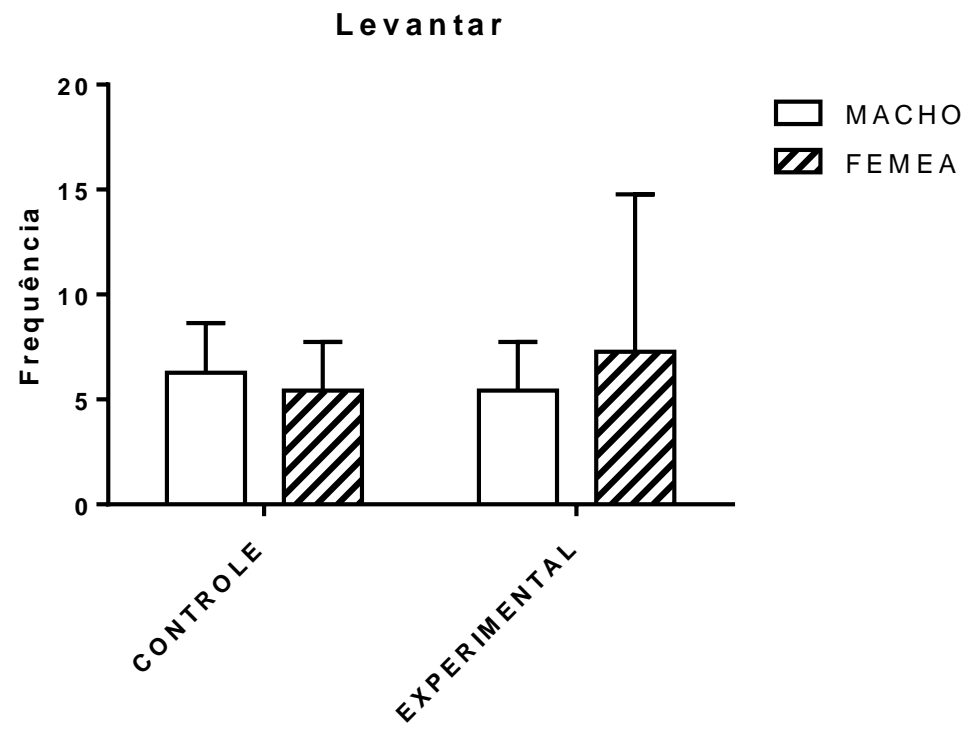

Figura 3: Efeitos da administração pós-natal de lipopolissacarídeo (LPS-50 $\mu \mathrm{g} / \mathrm{Kg}$ ) no quinto dia da lactação na frequência de levantar de ratos machos e fêmeas observados em campo aberto no PND21. São apresentadas as médias e respectivos erros - padrão. N=7/grupo. ANOVA de duas vias.

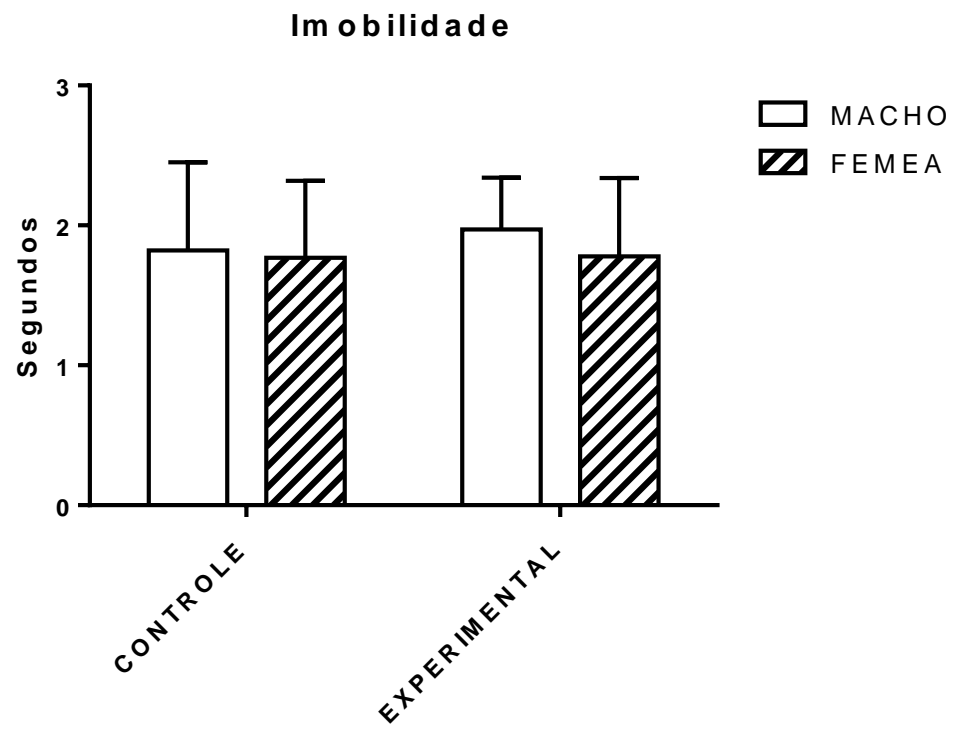

Figura 4: Efeitos da administração pós-natal de lipopolissacarídeo (LPS-50 $\mu \mathrm{g} / \mathrm{Kg}$ ) no quinto dia da lactação na duração (segundos) de imobilidade de ratos machos e fêmeas observados em campo aberto no PND21. São apresentadas as médias e respectivos erros-padrão. $\mathrm{N}=7$ /grupo. ANOVA de duas vias. 


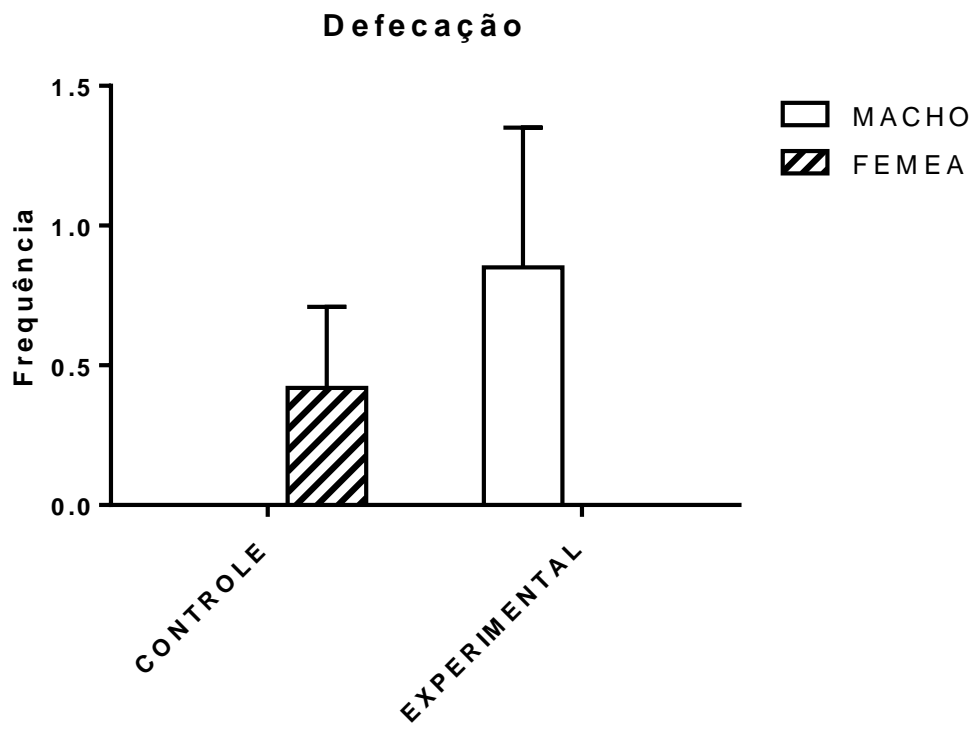

Figura 5: Efeitos da administração pós-natal de lipopolissacarídeo (LPS- 50 $\mu \mathrm{g} / \mathrm{Kg}$ ) no quinto dia da lactação na frequência de bolos fecais de ratos machos e fêmeas observados em campo aberto no PND21. São apresentadas as médias e respectivos erros-padrão. $\mathrm{N}=7$ /grupo. ANOVA de duas vias.

\subsection{Atividade Geral em Campo aberto na idade adulta (PND75)}

As figuras - (6-10) ilustram os efeitos da administração pós-natal de lipopolissacarídeo (LPS) no PND5 na atividade geral de ratos machos e fêmeas observadas em campo aberto no PND75 de vida. Assim, a ANOVA de duas vias aplicada à frequência de locomoção indicou que o tratamento não alterou o resultado $(\mathrm{F}(1 / 24)=0.13, \mathrm{P}=0.72)$, mas o $\operatorname{sexo} \operatorname{sim}(\mathrm{F}(1 / 24)=4.75, \mathrm{P}=0.3)$ não havendo interação entre os fatores $(\mathrm{F}(1 / 24)=0.18, \mathrm{P}=0.67)$. $\mathrm{O}$ Teste $\mathrm{T}$ indicou que as fêmeas do grupo experimental tiveram maior locomoção $(\mathrm{P}=0.02)$ que as do grupo experimental macho. Da mesma forma, com relação à frequência de levantar, a ANOVA de duas vias indicou que o tratamento não alterou o resultado $(\mathrm{F}(1 / 24)=3.43, \mathrm{P}=0.04)$, mas o sexo $\operatorname{sim}(\mathrm{F}(1 / 24)=4.54, \mathrm{P}=$ $0.04)$ não havendo interação entre os fatores $(\mathrm{F}(1 / 24)=3.70, \mathrm{P}=0.06)$. $\mathrm{O}$ Teste $\mathrm{T}$ indicou que as fêmeas do grupo experimental tiveram maior levantar $(\mathrm{P}=0.03)$ que as do grupo experimental macho. $\mathrm{O}$ mesmo teste não indicou diferenças significantes com relação à duração de limpeza [tratamento $=\mathrm{F}(1 / 24)=1.13, \mathrm{P}=0.29$ e sexo $=\mathrm{F}(1 / 24)=0.05, \mathrm{P}=0.82)]$ não havendo interação entre os fatores $(\mathrm{F}(1 / 24)=11.89, \mathrm{P}=0.00)$. Quanto à frequência de defecação tanto o tratamento $(\mathrm{F}(1 / 24)=18.54, \mathrm{P}=0.00)$ como o sexo $(\mathrm{F}(1 / 24)=31.51, \mathrm{P}<0.00)$ alteraram os resultados $)$, havendo interação entre os fatores $(\mathrm{F}(1 / 24)=17.27, \mathrm{P}=0.00)$. A ANOVA de uma via indicou que os ratos machos do grupo controle defecaram mais do que as ratas fêmeas do grupo controle, fêmeas do grupo experimental e machos do grupo experimental $(\mathrm{F}=2.43, \mathrm{P}<0.00)$. 


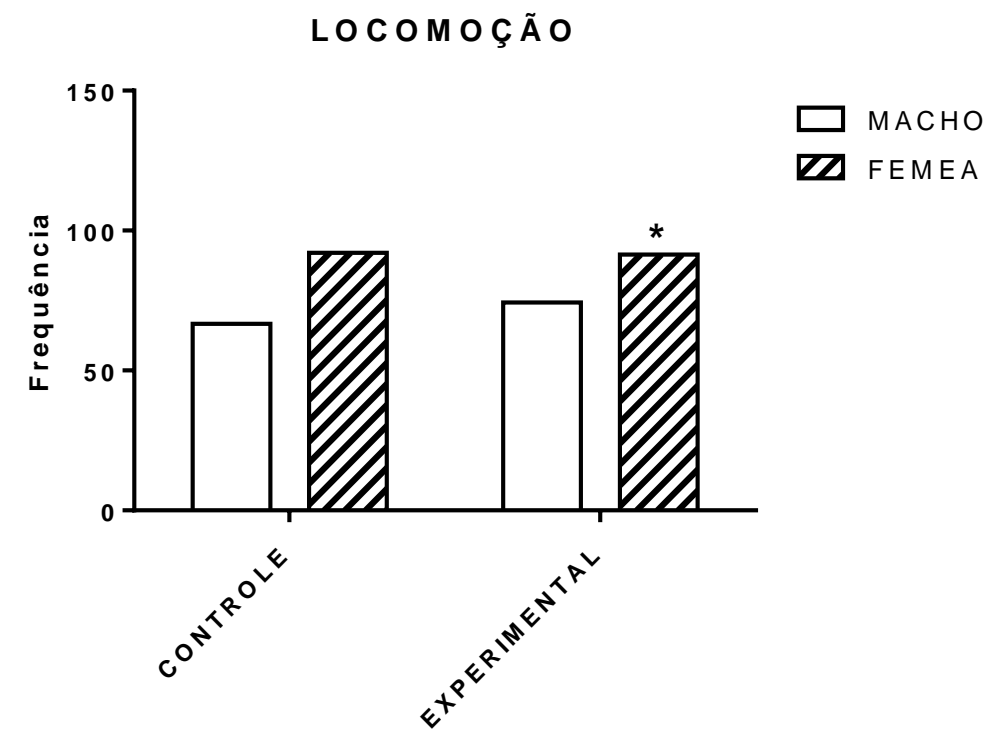

Figura 6: Efeitos da administração pós-natal de lipopolissacarídeo (LPS - $50 \mu \mathrm{g} / \mathrm{Kg}$ ) no PND75 na frequência de locomoção de ratos machos e fêmeas observados em campo aberto na idade adulta, desafiados com a mesma endotoxina $(100 \mu \mathrm{g} / \mathrm{Kg})$. São apresentadas as médias e respectivos erros-padrão. $\mathrm{N}=7 /$ grupo. ANOVA de duas vias. ${ }^{*} \mathrm{p}<$ 0,05 em relação ao grupo de ratos machos tratados com LPS.

\section{LEVANTAR}

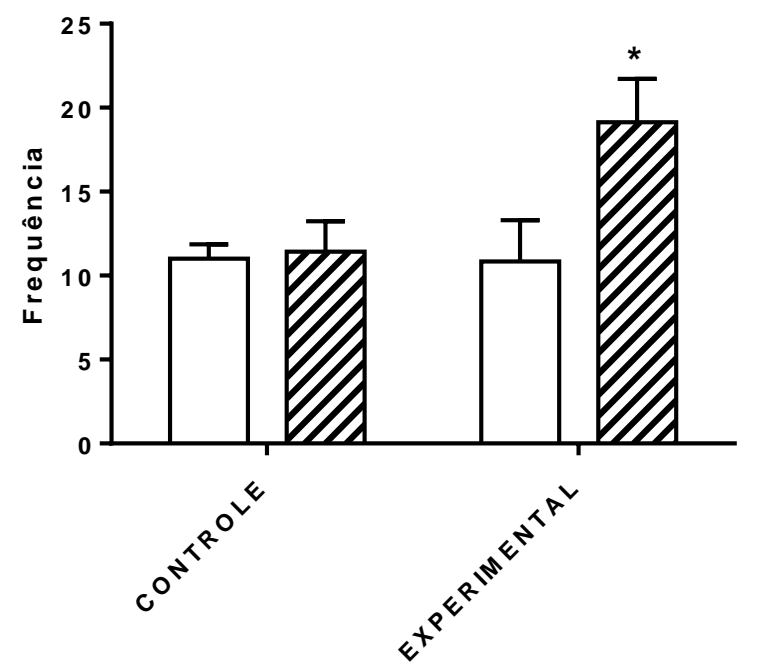

Figura 7: Efeitos da administração pós-natal de lipopolissacarídeo (LPS- $50 \mu \mathrm{g} / \mathrm{Kg}$ ) no PND75 na frequência de levantar de ratos machos e fêmeas observados em campo aberto na idade adulta, desafiados com a mesma endotoxina $(100 \mu \mathrm{g} / \mathrm{Kg})$. São apresentadas as médias e respectivos erros-padrão. $\mathrm{N}=7 /$ grupo. ANOVA de duas vias. * p $<0,05 \mathrm{em}$ relação ao grupo de ratos machos tratados com LPS. 
LIM PEZA

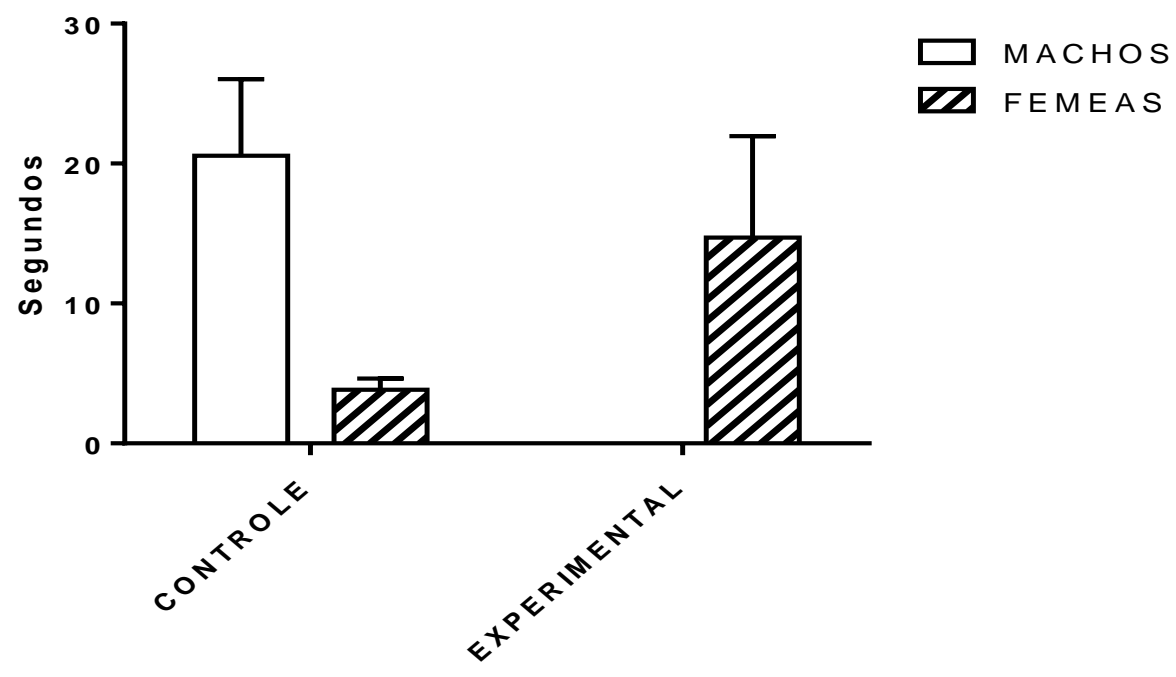

Figura 8: Efeitos da administração pós-natal de lipopolissacarídeo (LPS- $50 \mu \mathrm{g} / \mathrm{Kg}$ ) no PND75 na duração de imobilidade de ratos machos e fêmeas observados em campo aberto na idade adulta, desafiados com a mesma endotoxina $(100 \mu \mathrm{g} / \mathrm{Kg})$. São apresentadas as médias e respectivos erros-padrão. N=7/grupo. ANOVA de duas vias.

BOLOS FECAIS

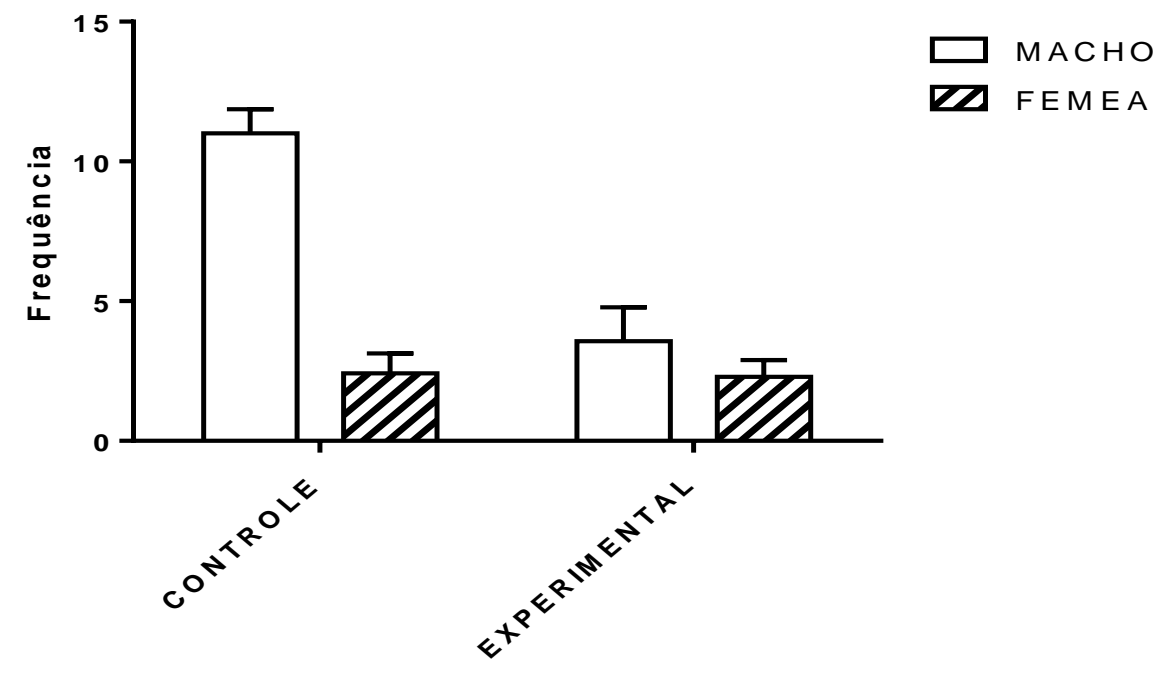

Figura 9: Efeitos da administração pós-natal de lipopolissacarídeo (LPS- $50 \mu \mathrm{g} / \mathrm{Kg}$ ) no PND75 na frequência de defecação de ratos machos e fêmeas observados em campo aberto na idade adulta, desafiados com a mesma endotoxina $(100 \mu \mathrm{g} / \mathrm{Kg})$. São apresentadas as médias e respectivos erros-padrão. $\mathrm{N}=7 / \mathrm{grupo}$. ANOVA de duas vias, seguida pela ANOVA de uma via. $* \mathrm{p}<0,05$ em relação ao grupo controle macho. 


\section{Discussão}

Os presentes resultados mostraram que a administração de LPS em filhotes machos e fêmeas de ratas no PND5, não alterou o peso corporal e a atividade geral observada em campo aberto no dia do desmame. Portanto, pode-se sugerir que a administração da endotoxina não alterou o desenvolvimento físico e comportamental destes filhotes, no que concerne ao peso corporal e à sua atividade geral. Neste sentido, a comparação dos diferentes parâmetros da atividade geral entre os filhotes machos e fêmeas, de ambos os grupos, não mostrou diferenças quanto ao gênero. Esta ausência de dimorfismo sexual é esperada desde que é determinada pelos hormônios gonadais (PALANZA, 2001), e na fase inicial da vida, estes animais não haviam alcançado a maturidade sexual. No entanto, filhotes tratados na infância, que receberam uma segunda dose de LPS na idade adulta, apresentaram alterações na atividade geral observada em campo aberto em relação àqueles ratos tratados com salina na infância e, que receberam o LPS na idade adulta. Além disto, estas alterações foram sexualmente dimórficas. Diversas evidências indicam que os cérebros feminino e masculino são sexualmente dimórficos. Nos cérebros humanos os dimorfismos são pequeno, sutis e difíceis de serem encontrados; núcleos hipotalâmicos variam em seus volumes quando comparamos homens e mulheres, mas as variações são tais que não se consegue ainda determinar um perfil a ser seguido (DAMIANI et al, 2005). Já nos roedores, é possível diferenciar o cérebro de um macho de uma fêmea baseando-se apenas no volume hipotalâmico, com pequena probabilidade de erro. Além disto, é fato conhecido que a variações no comportamento sexual dos animais são cíclica e ocorrem ao longo do tempo, em particular nas fêmeas. Foi por este motivo que neste trabalho fixou-se a fase do estro no ciclo estral das fêmeas para as observações comportamentais, de tal forma a minimizar os efeitos hormonais no comportamento destas fêmeas. O campo aberto foi introduzido por Calvin Hall, em 1934, esse teste foi primeiramente usado para avaliar a emocionalidade. O teste de campo aberto é considerado como um bom modelo animal de ansiedade por sua sensibilidade bidirecional a tratamentos farmacológicos, podendo avaliar o comportamento semelhante à ansiedade em varias espécies, incluindo animais transgênicos e camundongos Knouckout (CAROLA et al., 2002). O comportamento de roedores no campo aberto é sexualmente dimórfico, sendo que fêmeas exploram mais o campo aberto que machos. Neste trabalho, este fato foi confirmado quando da comparação entre ratos machos e fêmeas no que concerne a frequência de locomoção. De fato, a análise estatística indicou diferenças entre frequência de locomoção de machos e fêmeas, sendo que as fêmeas locomoveram-se mais que os machos. Esta diferença foi mais evidente nos animais tratados pós-natalmente com o LPS. Os mesmos resultados foram observados na frequência de levantar. Por outro lado, a frequência de defecar de ratos machos, do grupo controle, foi maior que nos demais animais. A defecação é tida como um índice de emocionalidade (BROADHURST, 1960). Portanto, estes resultados sugerem que o tratamento pós-natal com LPS exacerbou o dimorfismo sexual entre ratos machos e fêmeas quando expostos a um desafio com LPS na idade adulta. Além disto, parece que os ratos machos não tratados pós-natalmente com o LPS, mostraram maior emocionalidade quando receberam o LPS na idade adulta. Duas hipóteses podem ser feitas para explicar os resultados obtidos. A primeira propõe que fêmeas desenvolvem maior tolerância que os machos ao LPS e, a segunda, é que a administração pós-natal do LPS possa ter alterado a função motora das fêmeas e resultou em maiores frequências de locomoção e levantar. A administração de LPS promove comportamento doentio nos animais, caracterizada por redução na atividade geral, febre e redução no consumo de alimentos. Segundo Hart (1998) o conjunto de alterações apresentadas por animais doentes, coletivamente denominadas de comportamento doentio, estava longe de ser o resultado de uma depressão geral e inespecífica do SNC, correspondia a um conjunto organizado de 
modificações fisiológicas e comportamentais; isto é, existia uma base biológica especifica (e não patológica) para o comportamento de animais doentes. Existem diferenças sexuais no sistema imune favorecendo as fêmeas em geral (ASHOWN et al, 2007; ENGELAND et al., 2003, GAILLARD \& SPINEDI, 1998; LAHITA, 2000; MARTIN, 2000, SPINEDI et al., 2002, NASCIMENTO et al 2014). As fêmeas têm a função imune mais ativa, tanto do sistema imune humoral, quanto ao mediado por células, também denominado inato (BILBO \& NELSON, 2001; ENGELAND et al., 2003; SCHUURS \& VERHUL, 1990; ZUK \& MCKEAN, 1996). Este dimorfismo sexual origina-se principalmente de ação de hormônios gonadais, tendo a testosterona efeito supressivo em ambas vertentes do sistema imune (OLSEN et al., 2001; OLSEN \& KOVACS, 2001; RODEN et al., 2004; VISELLI et al 1997), enquanto o estrógeno aumenta a imunidade (GIGLIO et al., 1994). Ainda as fêmeas desenvolvem tolerância ao efeito do LPS de forma mais rápida do que machos (ENGELAND et al., 2003), sendo o fenômeno dependente da fase do ciclo estral e da fase fisiológica (ENGELAND et al., 2006; NASCIMENTO et al., 2013). Nestes últimos trabalhos, os autores mostraram que na fase de proestro não se verifica tolerância ao LPS, enquanto que nas demais, ela ocorre. Mostra também que fêmeas lactantes e virgens no estro, que receberam o mesmo tratamento com LPS, manifestam febre em horários diferentes. Portanto, a escolha da fase de estro empregada neste trabalho foi apropriada para mostrar possível tolerância ao LPS. Assim, o aumento das frequências de locomoção e levantar observadas nas ratas tratadas pós-natalmente com o LPS, e desafiada na idade adulta com a mesma endotoxina, podem ser interpretadas como uma maior tolerância aos efeitos do LPS, a qual é sexualmente dimórfica.

\section{Conclusão}

A ativação do sistema imune no início da vida em fêmeas atenua de forma significante as respostas a uma outra infecção, aumentando as frequências de locomoção e levantar em ratas tratadas pós-natalmente com o LPS e desafiadas na idade adulta com a mesma endotoxina fato que não ocorre em machos. Estes dados sugerem que fêmeas desenvolvem maior tolerância aos efeitos do LPS quando expostos na infância à mesma endotoxina

\section{Agradecimentos}

Agradeço à Fundação de Amparo à Pesquisa do Estado de São Paulo pelo apoio financeiro (2010/01855-1) e ao Departamento de Patologia da Faculdade de Medicina Veterinária e Zootecnia, Universidade de São Paulo, onde este trabalho foi realizado.

\section{Referências}

AFIFI, A.L.K.; BERGMAN, R.A. Neuroanatomia Funcional 1. ed. Roca São Paulo 2007.

ALVES, G.J.; PALERMO-NETO, J. Neuroimunomodulação: sobre o diálogo entre os sistemas nervoso e imune. Revista Brasileira de Psiquiatria, v.34, p.6-12, 2007.

ASHDOWN, H.; DUMONT, Y.; NG, M.; POOLE, S.; BOKSA, P.; LUHESHI, G. N. The role of cytokines in mediating effects of prenatal infection on the fetus: implications for schizophrenia. Molecular Psychiatry, v.11, n.1, p. 47-55, 2006. 
BASSO, A.S.; PINTO, F.A.; RUSSO, M.; BRITTO, L.R.; DE SA-ROCHA, L.C.; PALERMONETO, J. Neural correlates of IgE-mediated food allergy. Journal of Neuroimmunology, v. 140 p. 69-77, 2003.

BERNARDI, M. M. Exposição aos medicamentos durante o período perinatal. In: Farmacologia Aplicada a Medicina Veterinária. SPINOSA, H. S.; GÓRNIAK, SL; BERNARDI, M.M. Guanabara Koogan, Rio de Janeiro, 2006.

BILBO, S.D.; YIRMIYA, R.; AMAT, J.; PAUL, E.D.; WATKINS, L.R.; MAIER, S.F. Bacterial infection early in life protects against stressor-induced depressive-like symptoms in adult rats. Psychoneuroendocrinology, v. 33(3), p. 261-9. 2008.

BROOKS, G. F.; BUTEL, J. S.; MORSE, S. A. Estrutura cellular. In: Jawetz, Melnick \& Adelberg: Microbiologia médica. 21. ed. Rio de Janeiro: Guanabara Koogan, p. 6-30, 2000.

CAROLA, V.; D'OLIMPIO F.; BRUNAMONTI E.; MANGIA, F.; RENZI, P. Evaluation of the elevated plus-maze and open-field tests for the assessment of anxiety-related behaviour in inbred mice. Behavioural Brain Research, v. 134 (1-2), p. 49-57, 2002.

ENGELAND, C.G.; KAVALIERS, M.; OSSENKOPP, K.P. Sex differences in the effects of muramyl dipeptide and lipopolysaccharide on locomotor activity and the development of behavioral tolerance in rats. Pharmacology Biochemistry and Behavior, v. 74(2), p. 433-47, 2003.

ENGELAND, C.G.; KAVALIERS, M.; OSSENKOPP, K.P. Influence of the estrous cycle on tolerance development to LPS-induced sickness behaviors in rats. Psychoneuroendocrinology, v. 31(4), p.510-25. 2006

GAILLARD, R.C. \& SPINEDI E. Sex- and stress-steroids interactions and the immune system: evidence for a neuroendocrine-immunological sexual dimorphism. Domestic Animal Endocrinology, v.15, p. 345-352, 1998.

GAYLE, D.A.; BELOOSESKY, R.; DESAI, M.; AMIDI, F.; NUÑEZ, S.E.; ROSS, M.G. Maternal LPS induces cytokines in the amniotic fluid and corticotropin releasing hormone in the fetal rat brain. American Journal of Physiology. Regulatory, Integrative and Comparative Physiology, v.286(6), p. R1024-9, 2004.

GIGLIO, T.; IMRO, M.A.; FILACI, G.; SCUDELETTI, M.; PUPPO, F.; DE CECCO, L.; INDIVERI, F.; COSTANTINI, S. Immune cell circulating subsets are affected by gonadal function. Life Sciences, v. 54(18), p. 1305-12. 1994.

HALL, C.S. Emotional behavior in the rat. I. Defecation and urination as measures of individual differences in emotionality. Journal of Comparative Psychology, v. 18, p. 385-403, 1934. 
HART, B.L. Biological basis of the behavior of sick animals. Neuroscience \& Biobehavioral Reviews, v. 12(2), p.123-37, 1998.

LAHITA, R.G. Gender and the immune system. The journal of gender-specific medicine, v. 3(7), p.19-22.2000.

LEVITON, A.; DAMMANN, O.; DURUM, S.K. The adaptive immune response in neonatal cerebral white matter damage. Annals of Neurology, v. 58, n. 6, p. 821-828, 2005.

MARTIN, J.T. Sexual dimorphism in immune function: the role of prenatal exposure to androgens and estrogens. European Journal of Pharmacology, v. 405(1-3), p.251-61, 2009

MEIBOHM, B.; BEIERLE, I.; DERENDORF, H. How important are gender differences in pharmacokinetics? Clinical Pharmacokinetics, v.41(5), p.329-42, 2002.

NASCIMENTO, A.; BERNARDI, M.; PECORARI, V.; MASSOCO, C.; FELICIO, L. Temporal analysis of lipopolysaccharide-induced sickness behavior in virgin and lactating female rats. Neuroimmunomodulation, v. 20(6), p. 305-12, 2013.

NASCIMENTO, A.F.; ALVES, G.J.; MASSOCO, C.O.; TEODOROV, E.; FELICIO, L.F; BERNARDI, M.M. Lipopolysaccharide-induced sickness behavior in lactating rats decreases ultrasonic vocalizations and exacerbates immune system activity in male offspring. Neuroimmunomodulation, v. 22(4), p. 213-21, 2015

OLSEN, N.J.; GU, X.; KOVACS, W.J. Bone marrow stromal cells mediate androgenic suppression of B lymphocyte development. Journal of Clinical Investigation, v.108(11), p. 1697-704, 2001

OLSEN, N.J.; KOVACS,W.J. Effects of androgens on T and B lymphocyte development. Journal of Immunology Research, v. 23(2-3), p. 281-8, 2001.

PALANZA, P. Animal models of anxiety and depression: how are females different? Neuroscience and Biobehavioral Reviews, v. 25, p. 219-233, 2001.

PIGOTT, T.A. Anxiety disorders in women. Psychiatric Clinics of North America, p. 26(3), v. 621-72, 2003.

RIECHER-RÖSSLER, A.; HÄFNER, H. Gender aspects in schizophrenia: bridging the border between social and biological psychiatry. Acta Psychiatrica Scandinavica, v. 407, p. 58-62, 2000.

ROADHURST, P. L. Experiments in psychogenetics: Applications of biometrical genetics to the inheritance of behaviour. In: EYSENCK, H. J. Experiments in personality. London: Routledge \& Kegan Paul, v. 1, p.1-256.1960.

RODEN, A.C.; MOSER, M.T.; TRI, S.D.; MERCADER， M.; KUNTZ， S.M.; DONG, H.; HURWITZ, A.A.; MCKEAN, D.J.; CELIS, E.; LEIBOVICH, B.C.; ALLISON, J.P.; KWON, E.D. Augmentation of $\mathrm{T}$ cell levels and responses induced by androgen deprivation. The Journal of Immunology, v.173(10), p. 6098-108, 2004 
SPINEDI, E.; GAILLARD, R.C.; CHISARI, A. Sexual dimorphism of neuroendocrine-immune interactions. Frontiers of Hormone Research, v. 29, p. 91-107, 2002

SCHUURS, A.H.; VERHEUL, H.A. Effects of gender and sex steroids on the immune response. Journal of Steroid Biochemistry, v. 35(2), p.157-72, 1993

TENK, C.M.; KAVALIERS, M.; OSSENKOPP K.P. Sexually dimorphic effects of neonatal immune system activation with lipopolysaccharide on the behavioral response to a homotypic adult immune challenge. International Journal of Developmental Neuroscience, v.26, p. 331-8, 2008

VISELLI, S.M.; REESE, K.R.; FAN, J.; KOVACS, W.J.; OLSEN, N.J. Androgens alter B cell development in normal male mice. Cellular Immunology, v. 182(2), p. 99-104, 1997.

ZUK, M.; MCKEAN, K.A. Sex differences in parasite infections: patterns and processes. International Journal for Parasitology, v. 26(10), p. 1009-23, 1996. 